\title{
Tinjauan Etika Dokter sebagai Eksekutor Hukuman Kebiri
}

\author{
Soetedjo ${ }^{\mathrm{T}, 2}$, Julitasari Sundoro ${ }^{\mathrm{T}, 3}$, Ali Sulaiman ${ }^{\mathrm{I}}$ \\ ${ }^{\mathrm{I}}$ Majelis Kehormatan Etik Kedokteran Pengurus Besar Ikatan Dokter Indonesia \\ ${ }^{2}$ Departemen Neurologi, Rumah Sakit Umum Daerah Dr. Moewardi, Surakarta, Jawa Tengah \\ ${ }^{3}$ The Indonesian Technical Advisory Group on Immunization (ITAGI), Ministry of Health
}

\section{Kata Kunci}

Dokter, eksekutor, kebiri

Korespondensi

contact@ilmiah.id

\section{Publikasi}

(C) 20I8 JEKI/ilmiah.id

\section{DOI}

I0.26880/jeki.v2i2.I8

Tanggal masuk: ıо April 2018

Tanggal ditelaah: 6 Mei 2018

Tanggal diterima: то Mei 2018

Tanggal publikasi: I2 Juni 2018
Abstrak Dewasa ini, kejahatan seksual sangat mudah ditemui, mulai dari kasus pelecehan seksual hingga pemerkosaan yang berujung pada tindakan pembunuhan. Kejahatan tersebut bahkan tidak memandang bulu, baik pria maupun wanita, dewasa hingga anak-anak dapat menjadi korban dari pelaku kejahatan seksual. Paedofil merupakan orang dengan gangguan dorongan seks berlebih dengan target anak-anak di bawah umur. Menanggapi peningkatan tren kejahatan paedofilia, pemerintah mengeluarkan UU No. I7 Tahun 2016 yang menetapkan hukuman kebiri kimia bagi para pelaku sebagai bentuk perlindungan terhadap anak. Dokter sebagai profesi yang memiliki kompetensi terbaik di bidang kesehatan (kemanusiaan) kemudian menghadapi dilema terkait tinjauan etik kedokteran yang ada terhadap kasus ini. Ikatan Dokter Indonesia (IDI) telah mengeluarkan fatwa penolakan dokter sebagai eksekutor kebiri yang dinilai dapat mencederai sumpah profesi, mengingat efektivitas kebiri yang masih dipertanyakan dan risiko komplikasi lain yang harus dihadapi terpidana dengan hukuman kebiri.

Abstract Nowadays, sexual crimes are becoming more common, ranging from sexual harassments to rape-murder cases. Such crimes are indiscriminate, either men or women, adults to children can become victims of sex offenders. Pedophiles are people with excess sex drive disorder targeting minors. In response to increasing trend of pedophilia crimes, the government issued Law no. I7 of 2016 which established chemical castration penalty as a form of child protection. Doctors as profession with best competence in the field of health (humanity) then must face medical ethical dilemma regarding this penalty. The Indonesian Doctors Association (IDI) has issued a refusal on doctors as castration executor, which is believed to violate the profession oath, given the questionable effectiveness of such method and the risk of other complications which comes with it.

\section{PENDAHULUAN}

Dalam penjatuhan hukuman pidana berupa hukuman mati yang melibatkan peran dokter di dalamnya, regulasi antara organisasi profesi dengan aparat penegak hukum menjadi hal fundamental yang dibutuhkan agar keterlibatan profesi kedokteran tersebut tidak mencederai sumpah profesi. Dengan demikian, profesi kedokteran yang menjunjung asas do no harm, ketika dihadapkan dengan kewajibannya dalam membantu proses peradilan dapat tetap menjalankan prosedur tanpa mencederai nilainilai etika kedokteran yang ada. ${ }^{1}$

Peran dokter tidak menimbulkan dilema yang besar pada eksekusi hukuman mati di Indonesia karena tugasnya hanya meyakinkan eksekutor bahwa terhukum sudah meninggal atau belum. Kehadiran dokter sebagai eksekutor kebiri dinilai diperlukan sebagai profesi dengan kompetensi yang mampu mengurangi rasa sakit bagi narapidana yang dijatuhi hukuman tersebut. 
Pertanyaannya, seorang dokter yang pada hakikatnya mempunyai kompetensi untuk membantu mengurangi gangguan kesehatan pada pasien sakit, dapatkah prinsip tersebut diputarbalikkan sekalipun dalam ranah hukum peradilan? Untuk menjawab pertanyaan di atas, dibuatlah tinjauan etika ini.

\section{HASIL DAN PEMBAHASAN}

\section{Kebiri (Kastrasi)}

Kebiri atau kastrasi merupakan tindakan bedah dan/atau penggunaan bahan kimia dengan tujuan untuk menghilangkan fungsi organ reproduksi berupa testis pada jantan maupun ovarium pada betina. ${ }^{2}$ Berdasarkan pengertiannya, prosedur kebiri kemudian dikelompokkan menjadi kebiri fisik dan kebiri kimia. Pada kebiri fisik, operator melakukan pengangkatan total pada organ reproduksi, yakni testis maupun ovarium. Pada kebiri kimia, tindakan seperti di atas tidak dilakukan, melainkan diganti dengan pemberian senyawa kimia yang mampu memperlemah atau menghilangkan fungsi dari hormon seks. Secara patofisiologi, kebiri kimia dilakukan dengan menyuntikkan hormon anti-testosteron ke dalam tubuh terpidana. Hormon tersebut bekerja dengan cara menekan produksi dan aktivitas testosteron sehingga tidak memunculkan pacuan libido selama orang tersebut berada dalam pengaruh obat tersebut.

Demi menjunjung nilai kemanusiaan, perlu dihindari penggunaan zat nekrotikans yang berefek permanen. Oleh karena zat kimia memiliki periode kerja yang tidak menetap, efek dari kebiri kimia ini semakin lama akan semakin menghilang (reversible) dan orang dengan kebiri kimia dapat memiliki fungsi seksualnya kembali secara normal, seperti kemampuan ereksi pada pria dan libido.

Perlu diwaspadai bahwa penurunan kadar hormon testosteron akan berdampak pada gangguan fungsi organ tubuh lainnya, seperti atrofi otot, pengeroposan tulang, berkurangnya sel darah, dan gangguan pada fungsi kognitif. Itulah sebabnya, perlu dilakukan pemantauan kesehatan pada terpidana kebiri kimia.

\section{Sejarah Hukuman Kebiri}

Cheney dalam bukunya menuliskan bahwa tindakan kebiri pertama sudah dilakukan sejak sekitar 8.000 tahun silam dengan objek hewan ternak betina. Adapun riwayat tindakan kebiri pertama pada manusia tidak banyak diketahui, tetapi diperkirakan hal tersebut terjadi di Mesir pada 2.600 SM di mana tindakan tersebut dilakukan terhadap budak laki-laki oleh majikannya dengan tujuan agar budak tersebut menjadi lebih patuh terhadap majikannya sebagai penjaga permaisuri dan putri-putri raja. ${ }^{3}$

Menurut kepercayaan kekaisaran Cina dan Korea, kebiri dilakukan dengan tujuan untuk mempertahankan status sosial di masa tersebut. Tindakan ini digunakan untuk menjaga dan melindungi istri mereka ketika para kaisar tersebut bertugas ke luar istana. ${ }^{3}$

Sementara itu di Roma, praktik kebiri dilarang oleh pemerintah karena pengangkatan testis menjadi hal yang dianggap bertentangan dengan norma kepercayaan tradisional di sana. Khususnya bagi anak laki-laki sebelum masa pubertas, tindakan kebiri dipercaya mampu memengaruhi perubahan pita suara hingga 95\% ke nada tinggi. Akan tetapi, pada era selanjutnya berkembang tren suara nyaring (soprano) di dunia barat sehingga praktik kebiri menjadi marak dilakukan oleh penyanyi pria yang menekuni dunia seriosa. ${ }^{3}$

Di zaman modern ini, tindakan kebiri dilakukan dengan tujuan sebagai sanksi pidana terhadap pelaku kejahatan seksual seperti pemerkosa dan paedofil di berbagai negara. ${ }^{3}$ Setiap negara menerapkan metode kebiri yang beragam. Sebut saja Republik Ceko dan Jerman adalah negara yang memberlakukan kebiri fisik berupa pengangkatan testis bagi para paedofil sebagai upaya kendali dari dorongan seksual abnormal yang dimiliki pelaku. Adapun hukuman kebiri kimia diberlakukan oleh beberapa negara seperti Rusia dan Korea Selatan bagi para pelaku kejahatan seksual yang berisiko mengulang kejahatannya setelah dilakukan konsultasi dengan psikiater. ${ }^{3}$ 


\section{Hukuman Kebiri di Indonesia}

Padatahun2016, pemerintah mengeluarkan Undang-Undang (UU) nomor 17 tahun 2016 sebagai penetapan dari Perpu nomor 1 tahun 2016 tentang perubahan kedua atas UU nomor 23 tahun 2002 mengenai Perlindungan Anak. Perubahan terkait kebiri terletak pada pasal 81 ayat (7) dengan bunyi sebagai berikut: "Terhadap pelaku sebagaimana dimaksud pada ayat (4) dan ayat (5) dapat dikenai tindakan berupa kebiri kimia dan pemasangan alat pendeteksi elektronik.". ${ }^{4}$ Berlakunya UU ini kemudian mengundang reaksi dari berbagai pihak, mulai dari organisasi pejuang penegakkan hak asasi manusia (HAM) hingga organisasi profesi kedokteran.

Tinjauan hukum terhadap muatan UU tersebut terdapat dalam Jurnal Konstitusi yang diterbitkan pada Maret 2017. Hukuman kebiri dinilai sebagai sebuah jawaban atas tingginya tuntutan publik terhadap pelaku kejahatan seksual di samping tidak optimalnya pemberlakuan hukum perlindungan anak selama ini di Indonesia. Akan tetapi berbagai pendekatan lain seperti dari segi sosiologi kemasyarakatan dan psikiatri perlu dipertimbangkan agar tindakan kebiri bukan menjadi solusi tunggal terhadap permasalahan ini. $^{5}$

\section{Sikap IDI terhadap Hukuman Kebiri}

Menyambung kontroversi penetapan UU nomor 17 tahun 2016, kontroversi lain kemudian timbul terkait penolakan Ikatan Dokter Indonesia (IDI) untuk menjadi eksekutor hukuman kebiri bagi pelaku kejahatan seksual pada anak. ${ }^{6}$ Dalam UU tersebut, dicantumkan metode hukuman kebiri berupa injeksi zat kimia anti-androgen dan bertujuan untuk mengurangi produksi hormon testosteron sehingga menurunkan dorongan seksual terpidana untuk sementara. ${ }^{4}$

Dalam pelaksanaannya, prosedur kebiri melibatkan risiko timbulnya rasa sakit dan komplikasi lainnya pada terpidana. Untuk itu, dokter dianggap sebagai profesi yang tepat untuk dijadikan eksekutor hukuman kebiri karena kompetensi yang dimilikinya, dibandingkan dengan profesi lainnya.
Di sisi lain, profesi kedokteran yang berpegang pada prinsip kedokteran berbasis bukti menilai bahwa efektivitas kebiri kimia sejatinya masih menjadi pertanyaan karena belum adanya studi double blind yang adekuat untuk membuktikan efektivitasnya. Hal ini kemudian menjadi landasan sikap IDI yang menolak keterlibatan dokter sebagai eksekutor kebiri. Penolakan IDI tersebut disampaikan melalui fatwa Majelis Kedokteran Etik Kedokteran (MKEK) Nomor 1 Tahun 2016 tentang Kebiri Kimia.?

Selain efektivitas kebiri, berbagai alasan lainnya turut mendasari penolakan IDI tersebut, seperti berbagai efek samping yang tidak diinginkan dari kebiri, kemungkinan permasalahan kejiwaan (psikis) yang menyebabkan kejahatan seksual, dan kesempatan bagi terpidana untuk melakukan tindak kriminal yang lebih ekstrem. ${ }^{8}$

Terlepas dari penolakan IDI, dokter polisi (dokpol) menyatakan bersedia melaksanakan prosedur tersebut apabila diperintahkan. Hal ini didasari oleh salah satu tugas Polisi Republik Indonesia (polri) yang harus melaksanakan ketetapan hukum dari Mahkamah Agung. ${ }^{9}$

\section{Tinjauan Etika}

Dalam Kode Etik Kedokteran (KODEKI) tahun 2012 pasal 5 dikatakan bahwa "setiap perbuatan/nasihat dokter yang mungkin melemahkan daya tahan psikis maupun fisik, wajib memperoleh persetujuan pasien/keluarganya dan hanya diberikan untuk kepentingan dan kebaikan pasien tersebut." Pada penjelasan pasal diterangkan bahwa melemahkan psikis maupun fisik pasien bertentangan dengan fitrah ilmu kedokteran kecuali bila terdapat alasan pembenar dari tindakan tersebut, seperti prosedur penghilangan fungsi saraf yang digunakan dalam pembiusan prabedah dan pemberian obat anti nyeri pada pasien dengan nyeri tak tertahankan. ${ }^{10}$

Mengacu pada hal tersebut, selain dari tindakan yang bertujuan menyembuhkan pasien, menghilangkan fungsi tubuh normal pasien bertentangan dengan tugas seorang dokter. Hal ini kemudian berlaku pada prosedur hukuman kebiri. Kendati bertujuan untuk 
kebaikan masyarakat luas dan pengendalian dorongan hormon seksual yang berlebihan pada pelaku kejahatan seksual, dalam hakikatnya mencederai fungsi normal tubuh pasien tetap tidak dapat dikatakan bebas dari pelanggaran terhadap etika kedokteran.

Meskipun demikian, bila dokter lepas tangan dalam hal ini, pertanyaan selanjutnya siapakah yang harus menggantikan peran dokter sebagai profesi dengan kompetensi yang mampu mengerti kesehatan fisik maupun psikis pasien dalam rangka mengurangi rasa sakit yang harus diderita oleh pelaku? Seorang eksekutor yang telah diberikan pelatihan kompetensi khusus kebiri kemudian menjadi salah satu jawaban untuk menengahi kepentingan antara hukum dan etika kedokteran.

\section{KESIMPULAN}

Dalam menegakkan keadilan, khususnya kasus paedofilia atau pemerkosaan anak yang sangat brutal terhadap kemanusiaan dan cenderungberulang, hakim dapatmenambahkan hukuman kebiri kimia. Sehubungan dengan tugas, fungsi dan wewenang tenaga medis atau kesehatan (dokter) yang adalah penyembuhan dan penghormatan hidup manusia secara alami, maka organisasi profesi telah mengeluarkan fatwa MKEK PB IDI No. 1 Tahun 2016 yang pada prinsipnya bahwa:

Tugas yang bertentangan dengan penyembuhan adalah bukan tugas profesi dokter

Bila hakim benar-benar memutuskan hukuman tambahan berupa kebiri kimia, maka tugas tersebut agar diperankan eksekusinya oleh pihak yang berwenang sebagai eksekutor seperti pada lazimnya

Ilmu kedokteran sangat memuliakan kesehatan siapa pun sebagai hak asasi manusia, karenanya para dokter harus menyadari tugasnya untuk mencegah, mendiagnosis, dan mengobati penyakit.

Dengan demikian profesi kedokteran dapat tetap menghormati keputusan hukum yang ada tanpa harus mencederai sumpah profesinya.

\section{KONFLIK KEPENTINGAN}

Tidak ada konflik kepentingan.

\section{UCAPAN TERIMA KASIH}

Penulis memberikan ucapan terima kasih kepada Fadlika Harinda yang telah membantu penulis dalam merealisasikan tulisan ini.

\section{REFERENSI}

1. Soetedjo, Soendoro J, Prawiroharjo P. Tinjauan etika: Dokter sebagai eksekutor hukuman pidana yang menyebabkan kematian, kecacatan, atau gangguan kesehatan. Jurnal Etika Kedokteran Indonesia. 2017;1(1);19-23. https://doi.org/10.26880/jeki.v1i1.5

2. Badan Pengembangan dan Pembinaan Bahasa Kementerian Pendidikan dan Kebudayaan Republik Indonesia. Kamus besar bahasa Indonesia [Internet]. 2016 [disitasi 2018 Apr 5]. Diunduh dari: http://kbbi.web.id

3. Cheney VT. A brief history of castration. $2^{\text {nd }}$ Ed. Bloomington; AuthorHouse: 2006.

4. Undang-Undang Republik Indonesia nomor 17 tahun 2016 tentang penetapan Perpu nomor 1 tahun 2016 tentang perubahan kedua atas Undang-Undang nomor 23 tahun 2002 mengenai perlindungan anak. 2016.

5. Mardiya NQ. Penerapan hukuman kebiri kimia bagi pelaku kekerasan seksual. Jurnal Konstitusi. Mar 2017;14(1):214-33.

6. Tisnadibrata IL. IDI tolak hukum kebiri [Internet]. Jakarta; 2016 [disitasi 2018 Apr 5]. Diunduh dari: http://www.benarnews. org/indonesian/berita/idi-tolak-hukumkebiri-06102016111236.html

7. Pengurus Besar Ikatan Dokter Indonesia. Fatwa Majelis Kehormatan Etik Kedokteran Indonesia nomor 1 tahun 2016. 
8. Rachmaningtyas A. Tugas dokter menyembuhkan alasan IDI tolak hukuman kebiri dinilai wajar [Internet]. Jakarta; 2016 [disitasi 2018 Apr 5]. Diunduh dari: http://nasional. kompas.com/read/2016/06/14/12395231/ tugas.dokter.menyembuhkan.alasan.idi.tolak. hukuman.kebiri.dinilai.wajar

9. Maharani E. Dokter kepolisian siap jadi eksekutor hukuman kebiri [Internet]. 2016 [disitasi 2018 Apr 5]. Diunduh dari: http://www.republika.co.id/berita/nasional/ hukum/16/06/14/o8r876335-dokterkepolisian-siap-jadi-eksekutor-hukuman-kebiri

10. Majelis Kehormatan Etik Kedokteran Indonesia. Kode etik kedokteran tahun 2012. Jakarta; 2012. 

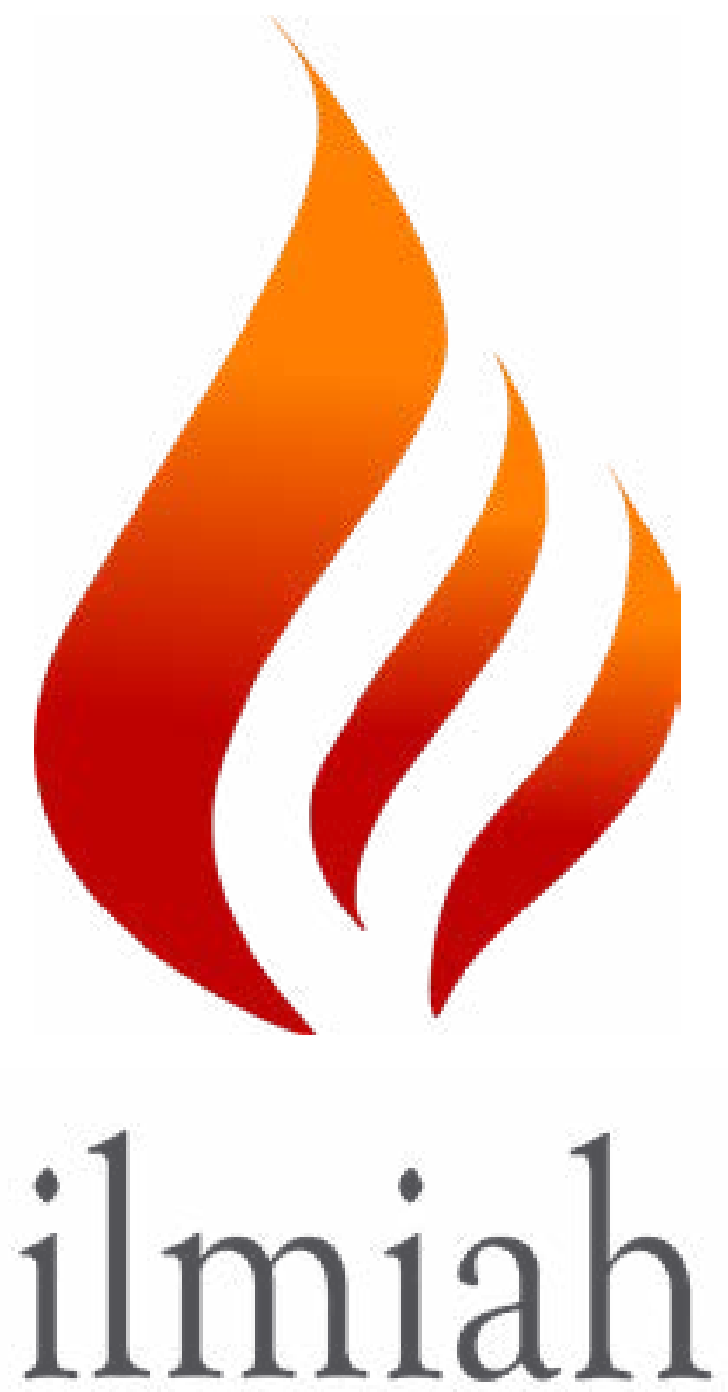

http://www.ilmiah.id your journal portal 